Research Article

\title{
Preliminary Measurements of Schumann's Resonances (SR) in the Greek
}

\author{
G. Tatsis ${ }^{1}$, C. I. Votis ${ }^{1}$, V. Christofilakis ${ }^{1}{ }^{, *}$, P. Kostarakis ${ }^{1}$, V. Tritakis ${ }^{2,3}$, C. Repapis ${ }^{2,3}$ and \\ P. Kalavrezos ${ }^{2}$ \\ ${ }^{1}$ Physics Department, Electronics-Telecommunications and Applications Laboratory, University of Ioannina, Ioannina, Greece \\ ${ }^{2}$ Marionopoulos-Kanaginis Foundation for the Environmental Sciences, Athens, Greece \\ ${ }^{3}$ Academy of Athens
}

Received 10 February 2016; Accepted 9 September 2016

\begin{abstract}
Schumann's Resonance (SR) measurements have been collected in the wider area of Ioannina by an equipment, designed and built in the laboratory of electronics and telecommunication of the University of Ioannina. Remarkable differences among measurements received in various epochs have been detected. At first, SR intensities taken around the Summer solstice are weaker than those taken around the Winter one, while SR intensities close to the Spring equinox are higher than those close to the Autumn equinox, on the average. Another obvious remark is a specific correlation between the SR intensity and the geomagnetic index Dst. Negative values of this index, which imply a disturb geomagnetic environment, correlate better with low SR intensity values. In the opposite, positive Dst values correspond to higher SR intensities. In general, the relative position of the Sun in relation to the earth as well as the solar/geomagnetic activity seems to affect the SR signals profile.
\end{abstract}

Keywords: Schumann resonance, Dst index, geomagnetic activity.

\section{Introduction}

Earth is a well-conducting sphere surrounded by a thin dielectric atmosphere and a good conducting ionospheric layer. The cavity between the lower ionosphere $(40-50 \mathrm{Km}$ height) and the terrestrial surface can be considered as a waveguide, resonator or capacitor

Several low frequency radio waves propagate in this area like atmospherics or VLF subionospheic propagations [1]. The lowest part of the ELF band, less than $50-60 \mathrm{~Hz}$ is occupied by a particular kind of waves called Schumann's Resonance (SR), from the name of the German W. O. Schumann who predicted their existence in early fifties, just after the discovery that an ionized layer surrounds the earth, the ionospheric layer [2].Schumann's resonances are quasistanding electromagnetic waves propagating along the earthionosphere cavity. They are travelling around the earth and return to the starting point. The basic SR frequency occurs when the phase difference between the starting point and the termination is equal to $2 \pi$. The ionosphere plasma density controls the upper frequency of the radio propagation which is around $20-40 \mathrm{MHz}$. The lower frequency is almost zero. If we consider the "length" of the cavity $2 \pi \mathrm{R}=40.000 \mathrm{Km}$ then the basic frequency of $\mathrm{SR}$ is given by the relation $\mathrm{f}_{\mathrm{n}}=\mathrm{c} / 2 \pi \mathrm{R}_{\mathrm{n}}=7,5 \mathrm{~Hz}$, where $\mathrm{c}$ the velocity of light and $\mathrm{n}=1$. In the same sense we expect higher harmonics for $n=2,3,4$ of about 15,23 and $30 \mathrm{~Hz}$. Main source of the SR is considered to be thunderstorms and lighting [3]. Schumann's Resonance is a very interesting but unexploited field of research because they seem to be related with many geophysical, and near-space phenomena. Various studies connect these waves with variations in atmospheric electricity, global temperature, aerosols in the atmosphere, earthquakes as well as psychological effects [4]

\section{Device and Techniques of SR Detection}

Detection and measurement of SR signals is a sensitive and difficult approach. The reason is that SR is a very weak signal, just a few tenths of picoTesla $\left(0,1-0,5 \times 10^{-12}\right.$ Tesla), something which implies a well designed coil to receive it and a very good amplifying system to pull this wave up from the noise. In addition, very good filtering is necessary for reducing every day electromagnetic noises produced from electric devices and electric transfer network. Taking in mind all these limitations, a device detecting SR has been designed and built in the laboratory of electronics and telecommunications of the Ioannina University. It is consisted of three main components. A coil of 40.000 turns around a $\mathrm{Mu}$ metal core for increasing permeability, a box where a series of amplifiers are contained and another box where the logger system lies. Part of the device is shown below, in the figure 1. A full description and technical characteristics of the device is going to be published in the near future. In our effort to take a good quality of measurements far from anthropogenic electrical activities, or public energy transfer lines we have selected a site forty kilometers far from the civil web of Ioannina by the banks of the Arachthos river.. In order to succeed our observations to be carried out under the same ionospheric conditions (heigh, ionization, thickness) and make our data comparable, all measurements have been received at noon 11-14 h local time.

\footnotetext{
*E-mail address: vachrist@uoi.gr

ISSN: $1791-2377$ @ 2016 Eastern Macedonia and Thrace Institute of Technology. All rights reserved.
} 


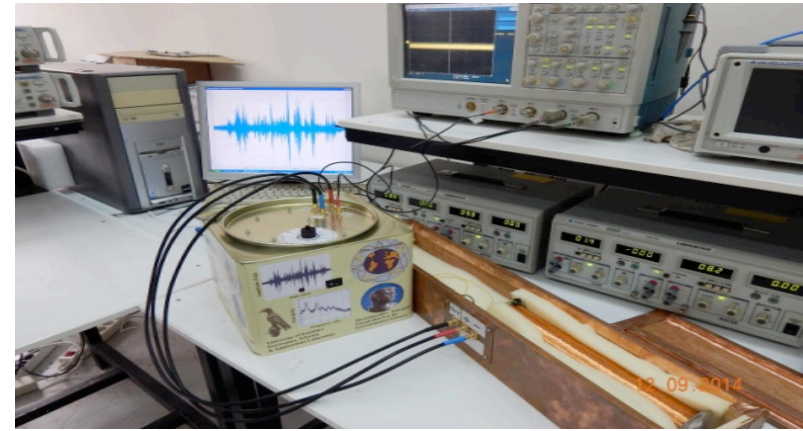

Fig. 1.Coil and amplifier box during tests in the laboratory.

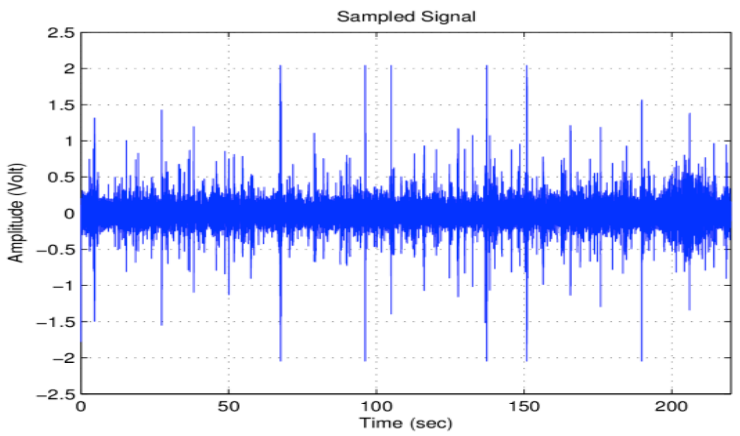

Fig.2. A typical 10-minutes recording of the lowest ELF part $0-100 \mathrm{~Hz}$.

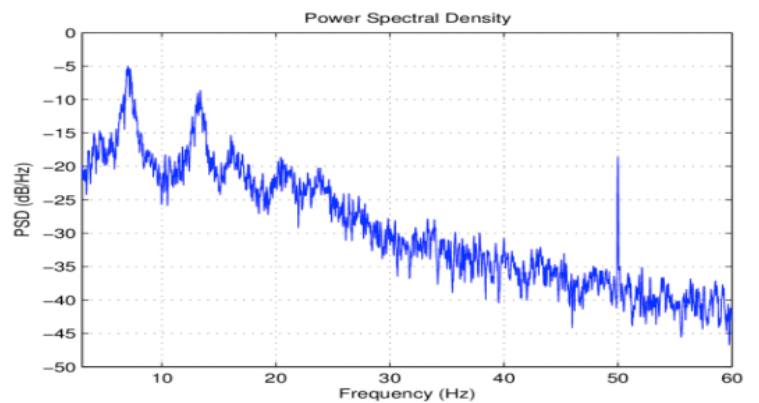

Fig. 3. Relevant spectrum of the above recording. The four typical peaks of SR are obvious around 7,13,21 and $28 \mathrm{~Hz}$. The high peak on the $50 \mathrm{~Hz}$ is induced by the public electric transfer network.

\section{Preliminary measurements and initial comments}

Remarkable differences among SR measurements collected in various epochs have been detected. At first SR intensities taken around the Summer solstice are weaker with flat peaks than those around Winter solstice, on the average. Figures 4 and 5 represent this remark, explicitly.

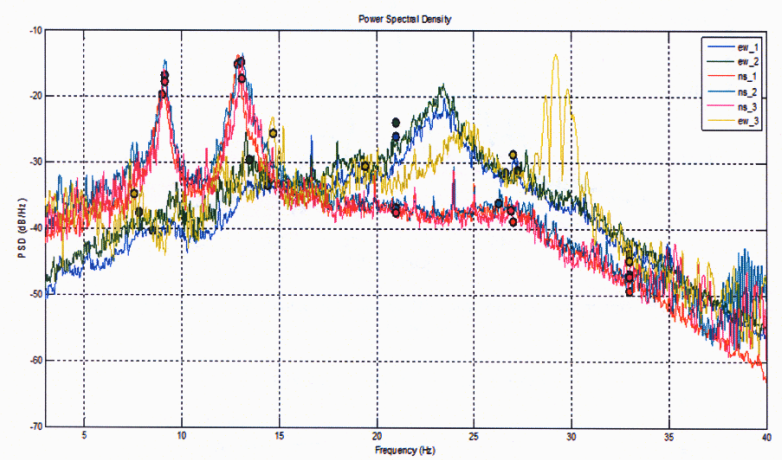

Fig. 4. A series of six 10-minutes recordings taken on the bank of Arachthos river on the 20/12/13 at noon (winter solstice). A N-S orientation of the coil represents high peaks around 8 and $13 \mathrm{~Hz}$ (red lines, mainly).An E-W orientation relates to $24 \mathrm{~Hz}$ (green and blue lines) and $28-30 \mathrm{~Hz}$ (yellow line).

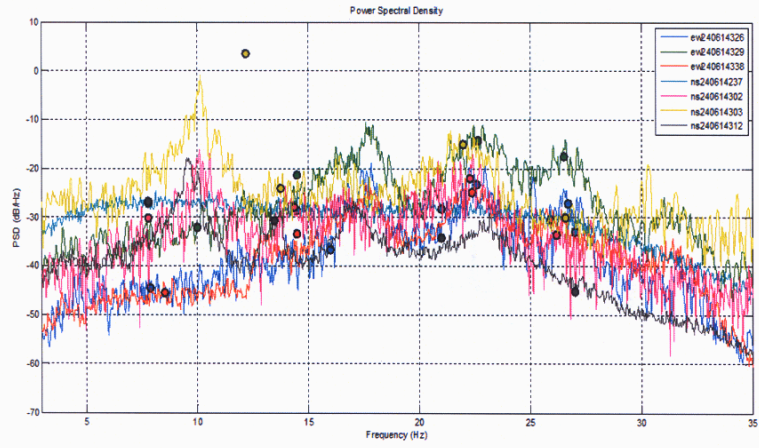

Fig. 5. A series of seven 10-minutes recordings taken in the same place with those of figure 4 on the 24/06/14 at noon (close to Summer solstice). Sharp peaks or distinct characteristics are absent from this figure.

Similar remarks can be underlined during the other two characteristic sites of the earth in relation to the sun, the equinoxes (21/03/ and 21/09).

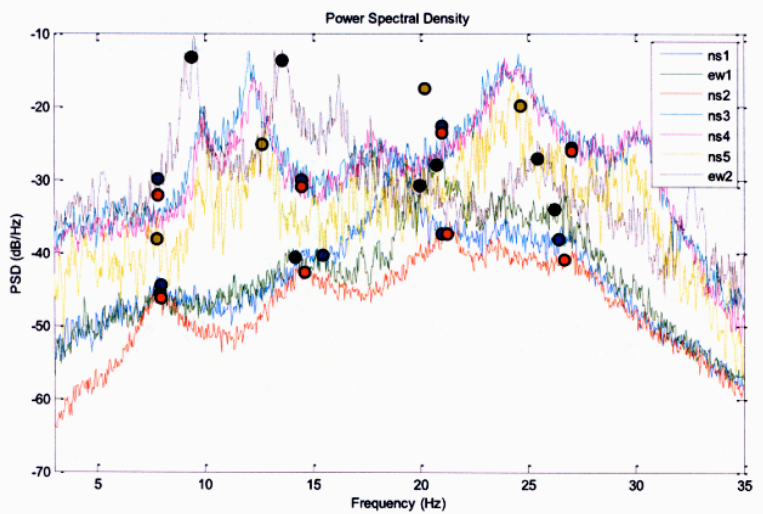

Fig. 6. A series of seven 10-minutes recordings taken on the 02/04/13 (close to the spring equinox), about at noon. Sharp peaks between 8 and $30 \mathrm{~Hz}$ are obvious.

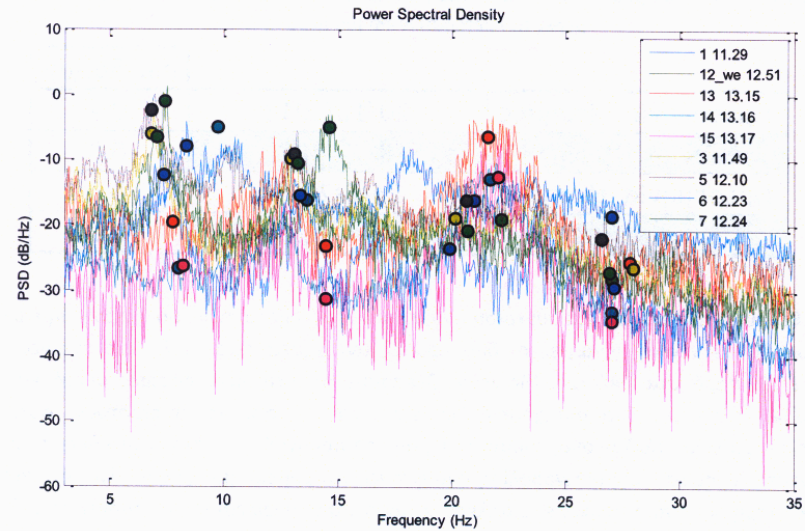

Fig.7. A series of nine 10-minutes recordings taken on the 10/10/13 (close to the autumn equinox), about at noon. There are peaks between 8 and $20 \mathrm{~Hz}$ but they are very weak and close to the noise.

\section{Additional remarks on the measurements above}

Geomagnetic and meteorological data during the dates when the above data have been received can provide very interesting information. In the following, hourly measurements of the geomagnetic Dst index as well precipitation recording, are presented in the tables 1 and 2 respectively. 
Table 1. Hourly Dst values during the dates when the measurements of the figures $4,5,6$ and 7 have been received.

\begin{tabular}{|c|c|c|c|c|}
\hline TIME (UT) & $\begin{array}{l}\text { Dst } \\
20 / 12 / 13 \\
\end{array}$ & $\begin{array}{l}\text { Dst } \\
24 / 6 / 14\end{array}$ & $\begin{array}{l}\text { Dst } \\
10 / 10 / 13\end{array}$ & $\begin{array}{l}\text { Dst } \\
2 / 4 / 14\end{array}$ \\
\hline 01 & -10 & 8 & -23 & 3 \\
\hline 02 & -9 & 12 & -33 & 4 \\
\hline 03 & -5 & 14 & -28 & 7 \\
\hline 04 & -4 & 9 & -28 & 9 \\
\hline 05 & -9 & 1 & -36 & 9 \\
\hline 06 & -7 & -2 & -38 & 7 \\
\hline 07 & -5 & -6 & -34 & 6 \\
\hline 08 & -6 & -5 & -28 & 5 \\
\hline 09 & -10 & -6 & -24 & 4 \\
\hline 10 & -13 & -4 & -21 & 2 \\
\hline 11 & 13 & -3 & 23 & 1 \\
\hline 12 & -13 & -2 & -25 & 5 \\
\hline 13 & -8 & -1 & -26 & 8 \\
\hline 14 & -5 & 0 & -24 & 8 \\
\hline 15 & -5 & 0 & -23 & 9 \\
\hline 16 & -4 & -1 & -22 & 8 \\
\hline 17 & -7 & -1 & -20 & 5 \\
\hline 18 & -10 & -1 & -19 & 4 \\
\hline 19 & -10 & 2 & -19 & 7 \\
\hline 20 & -9 & 9 & -19 & 7 \\
\hline 21 & -9 & 7 & -18 & 4 \\
\hline 22 & -9 & 3 & -20 & 2 \\
\hline 23 & -10 & -1 & -15 & 2 \\
\hline 24 & -12 & -4 & -16 & 0 \\
\hline
\end{tabular}

Table 2. Precipitation in Ioannina during the dates of our measurements

\begin{tabular}{l|l|l}
\hline Dates & $\begin{array}{l}\text { Precipitation } \\
\text { height (mm) }\end{array}$ & Epoch \\
\hline $01 / 04 / 13$ & 0,2 & Spring equinox \\
$02 / 04 / 13$ & 0,2 & (approx.) \\
$09 / 10 / 13$ & 4,8 & Autumn equinox \\
$10 / 10 / 13$ & 3,2 & (approx.) \\
$19 / 12 / 13$ & 0.0 & Winter solstice \\
$20 / 12 / 13$ & 0,2 & Summer solstice. \\
$23 / 06 / 14$ & 0,0 & \\
$24 / 06 / 14$ & 0,0 & \\
\hline
\end{tabular}

From the above table 1 it is clear that Dst negative values during the winter solstice $(20 / 06 / 13)$ are obviously higher than the values on the Summer solstice(24/06/14), something which implies some relation of the SR with solar/geomagnetic activity. It is very well known that the geomagnetic Disturbance Storm Index (Dst) expresses the magnetic condition of the ring current. Low Dst values correspond to high ring current activity which comes mainly from increased geomagnetic activity caused by solar
Disturbances. Another crucial remark which implies some relation of SR with various geophysical parameters is that all high SR presentation appears during or after even light precipitation, which underlines that a disturbed atmosphere favours SR enhancements [5].

From the table 2, it is clear that epochs with distinct SR recordings like equinoxes, occur when even light precipitation falls. In the opposite epochs with weak or no SR recordings like solstices, present no rain at all.

The presence of precipitation implies increased atmospheric electricity and lightning, which is considered to be the main source of SR creation.

\section{Conclusion}

Initial results from SR measurements in the wider area of Ioannina lead to the preliminary conclusions that this ELF band of waves presents some relation to meteorological and geophysical conditions. SR values collected close to the spring equinox and the winter solstice (21st of March and 21 st of December) are more intense than measurements close to autumn equinox (21st of September) and summer solstice( 21 st of June), evidently. Similar findings have been reported in China, recently [6].

Dst values during the dates when measurements were taken imply that high geomagnetic activity favors high SR occurrences. In addition, clear and sharp SR recordings seem to favored by even light precipitation. This is very reasonable because rainy weather means increased atmospheric electricity and lightning, which is the main source of the SR occurrence. Closing, it is necessary to mention that the strengthening of our conclusion needs additional measurements during epochs the earth flies by characteristic sites, in relation to the sun like equinoxes and solstices. Very confident conclusions on the SR properties can come up after a long, continues and reliable observation of them, something which implies that the installation of a permanent full-equipped station for SR detection in Greece, is more than necessary.

\section{Acknowledgment}

The authors express warm thanks to Mariolopoulos Kanaginis Foundation for Environmental Research for the prompt acceptance of this project and the generous support during its implementation.

\section{References}

1. Omorogiuwa Eseosa, "Efficiency Improvement of the Nigeria 330KV network using FACTS Device, University of Benin, Benin City 2011.

2. F.D Galiana, K Almeida, "Assessment and control of the Impact of FACTS devices on power system performance", IEEE Transactions on power systems, Vol .II, No 4, pp1931- 1936, November 1996.

3. E.Acha, C.R Fuerte-Esquirel, H .Ambriz-perez and C. AngelesCamacho, FACTS: Modelling and Simulation in power networks. Chictiester, U.K. Wiley, 2004.

4. V.K Sood, HVDC and FACTS Controllers Applications of static converters in power systems. Boston, M.A. Kluver Academic Publisher, 2004.
5. P. Moore and P.Ashmole, "flexible AC Transmission system, "Power Engineering Journal, Vol. 9, No.6, pp 282-286, Dec, 1995.

6. D.J. Gothan and G.T. Heydt, "Power flow control and power flow studies for system with FACTS Devices", IEEE Trans power system, Vol 13. No 1, February 1998.

7. K. Vijayakvmar, R.P Kumudinideri, "A new method for optimal location of FACTS Controllers Using Genetic algorithm", Journal of theoretical and applied information technology, 2005 - 2007 Jatit.

8. S.Gerbex, R. Cherkaoui and A.J. Germond. "Optimal location of multiple type FACTS Devices in a power system by means of 
Genetic algorithm. "IEEE Trans power systems. Vol. 16, pp. 537-544, August 2001.

9. T.T. Lie and W.Deng, "Optimal flexible AC Transmission systems (FACTS) Devices Allocation," Electrical power and Energy systems, Vol. 19, No 2, pp 125-134, 1994.

10. K.S. Verma, S.N Singh and H.O. Gupta, "Location of unified power flow controller for congestion management, "Electric power systems research, Vol. 58, pp 89-96, 2001.

11. S. Gerbex, R. Cherkaoul and A.J Germond, "Optimal location of multi-type FACTS devices in a power system by means of genetic algorithms IEEE Trans Power Systems, Vol. 16, pp 537544, August 2001.

12. T.T Lie and W. Deng,"Optimal Flexible AC Transmission systems (FACTS) devices allocation,"Electrical power \& Energy system, Vol.19, No.2, pp 125-134, 1997.
13. X. P. Wang, and L. P. Cao, Genetic Algorithms - Theory, Application and Software Realization, Xi'an Jiaotong University, Xi'an, China,1998.

14. F.T. Lie, and W.Deng"optimal flexible AC Transmission systems (FACTS) device allocation", Electrical power and Energy system,Vol.19,no 2,pp125-134,1997.

15. L. Gyugyl, C.D. Shauder and K. K. Sen,"static synchronous series compensator A solid state approach to the series compensation of transmission line," IEEE Transactions o power delivery Vol.12, no. 3, 1997.

16. S. Gerbex, R.Cherkaoui, and A.J.Germund,"optimal location of multi-type FACTS devices in a power system by means of genetic algorithms," IEEE Trans power systems, Vol. 16,pp537544, August 2001

17. X.P.Wang, and 1.P Cao,"Genetic Algorithms Theory, Application and Software Realization” ,Xi 'an Jiao tong University Xi'an,China, 1998 